\title{
The Long Magenstrasse in the Treatment of Super Obese Patients (Results over 5 Years after Surgery)
}

\author{
Giovanni Berbiglia $^{1}$, Mario Martinotti ${ }^{2 *}$, Gian Matteo Carena ${ }^{1}$, Elena Palamarciuc ${ }^{1}$, \\ Marina Fariseo ${ }^{1}$, Carlo Vassallo ${ }^{1}$ \\ ${ }^{1}$ Chirurgia II, Istituto Clinico "Città di Pavia", Pavia, Italy \\ ${ }^{2}$ Dipartimento di Chirurgia Generale, "Istituti Ospitalieri", Cremona, Italy \\ Email: "carlo.vassallo@grupposandonato.it
}

Received July 24, 2013; revised August 22, 2013; accepted August 30, 2013

Copyright (C) 2013 Giovanni Berbiglia et al. This is an open access article distributed under the Creative Commons Attribution License, which permits unrestricted use, distribution, and reproduction in any medium, provided the original work is properly cited.

\begin{abstract}
Background: The considerable increase in Obesity and especially the increase in super obese patients (Body Mass Index-BMI $\geq 50 \mathrm{Kg} / \mathrm{m}^{2}$ ) who require surgery lead doctors to search for surgery techniques which give good results in terms of a consistent and stable weight loss associated with low morbidity and good quality of life. The Long Magenstrasse (LM) intervention, born from combining two properly modified surgical procedures (Selective Vagotomy with pyloric divulsion and Mangestrasse \& Mill by Johnston) seems to have these characteristics according to our experience after operating on 660 patients. Methods: From October 2003 to October 2008 we treated 186 patients with LM. One hundred and sixty-two patients were regularly present to the annual follow-up, but 24 patients didn't turn up, therefore, they were contacted by phone. On average, surgery lasted approximately 80 minutes (range: $50-90$ minutes). Thirty patients were super obese with an average BMI of $57.4 \mathrm{Kg} / \mathrm{m}^{2} ; 156$ patients were grade II and III obese with an average BMI of $40.7 \mathrm{Kg} / \mathrm{m}^{2}$. Results: The average BMI of the 30 super obese patients decreased from $57.4 \mathrm{Kg} / \mathrm{m}^{2}$ to 35.9 $\mathrm{Kg} / \mathrm{m}^{2}$ one year after surgery, to $35.6,5$ years after surgery and it has remained stable until now. In the 156 patients suffering from II and III grade obesity, the average BMI decreased from $40.7 \mathrm{Kg} / \mathrm{m}^{2}$ to $27.8 \mathrm{Kg} / \mathrm{m}^{2}$ one year after surgery and it has remained stable until now. Out of all super obese diabetic patients, only one has partially maintained his/her therapy. Patients have reported a decreased appetite since the very first days of post-operative period with an early sense of satiety which is unchanged until today. Conclusions: A consistent and stable weight loss over 5 years after surgery even in Super Obese patients, a decrease in appetite with an early sense of satiety, a re-equilibrium of the metabolic syndrome in particular of Diabetes Mellitus, allow to classify LM among those surgical treatments with a mixed mechanism of action: both restrictive and functional, in particular, entero-hormonal and gastric neurosecretory.
\end{abstract}

Keywords: Super Obesity; Bariatric Surgery; Magenstrasse and Mill; Sleeve Gastrectomy; Gastric Partition; Gastric Bypass

\section{Introduction}

When performing Sleeve Gastrectomy (SG), each surgeon chooses the measures that he/she considers the most suitable ones: from 3 to $8 \mathrm{~cm}$ distant from the pylorus with conservation or non-conservation of the antrum, a calibration bougie ranging between 32 and 50 Fr. resulting in great variability in results especially over time [1,2].

Whereas, in the LM the surgical technique is very precise and its results are absolutely reproducible $[3,4]$.

The suture-section stretches from the angle of His up to $2-3 \mathrm{~cm}$ from the pylorus on a calibration bougie of 36 Fr., in this way the stomach appears uniformly tubular at

\footnotetext{
"Corresponding author.
}

the level of the small curvature (food tract). The rest of the stomach (corpus and fundus) is excluded from food transit while still producing gastric juices which flow into the $3 \mathrm{~cm}$ dimension prepyloric "Mill" (secretory pathway).

Without distal pouch, which could experience dilation over time, gastric conservation allows surgeons to stretch the suture-section up to $2-3 \mathrm{~cm}$ from the pylorus. In order to ease the transit of food bolus, a pyloric divulsion is carried out resulting in good gastric drainage which reduces the possibility of gastro-oesophageal reflux.

Another consequence of the long suture-section is selective vagotomy that determines a consistent reduction in gastric secretion $(20 \%-30 \%)$ [5] which is, anyway, 
proportional to the amount of food eaten (surgery restrictive aspect).

Differently from SG where corpus and fundus are removed, in the LM technique, despite being present, they are not transited by food, therefore, there are no stimuli to the production of ghrelin as it happens in gastric banding or in the traditional BPD (Biliopancreatic Diversion) $[6,7]$.

Another positive datum of LM is the physiological transit of food through the duodenum-jejunum without the "dumping syndrome" which is instead frequent in those techniques implying a direct gastro jejunal transit.

During a gastroscopy, where each part of the stomach can be studied, a biliary reflux inside the "Mill" has never been noticed, probably thanks to a simple pyloric divulsion instead of a real surgical pyloroplasty.

\section{Materials and Methods}

In October 2003 we started using LM for treating great obese patients; until December 2012, 660 patients were operated on with this procedure.

All patients underwent a pre-operative internistic-dietological screening with possible respiratory rehabilitation more or less protracted over time until reaching an Apnea/Hypopnea Index (AHI) inferior to 5.

From October 2003 to October 2008 we treated with LM 186 patients, 147 women (79\%) and 39 men (21\%) with an average age of 39 (range: 16 - 62) and an average BMI of $45 \mathrm{Kg} / \mathrm{m}^{2}$.

Thirty patients were super obese with an average BMI of $57.4 \mathrm{Kg} / \mathrm{m}^{2} ; 156$ patients were II and III grade obese with an average BMI of $40.7 \mathrm{Kg} / \mathrm{m}^{2}$ (Table 1 ).

Out of these 30 super obese patients, 21 were women and 9 were men with an average age of 39 (range 16 54); 16\% suffered from Pickwick syndrome, 36\% from dyslipidemia $16 \%$ was affected by hyperuricemia and $34 \%$ by arterial hypertension.

The average time of intervention with "open" surgery with median or left subcostal laparotomy lasted 80 minutes; in the other cases surgery was performed with videolaparoscopy or hand-assisted videolaparoscopy.

The pylorus divulsion was digitoclastic in "open" surgery or hand-assisted videolaparoscopic, pneumatic-endoscopic in case of videolaparoscopic procedure.

All patients underwent heparin prophylaxis and an

Table 1. Subjects baseline characteristics before Long Magenstrasse.

\begin{tabular}{ccc}
\hline & Obese (n. 156) & Superobese (n. 30) \\
\hline Men/Women $(N)$ & $70 / 116(156)$ & $8 / 22(30)$ \\
Age & $40.6 \pm 9.5$ & $39.3 \pm 9.8$ \\
Weight $(\mathrm{Kg})$ & $105 \pm 15(86-133.5)$ & $159 \pm 29.4(125-250)$ \\
BMI $\left(\mathrm{kg} / \mathrm{m}^{2}\right)$ & $40.7 \pm 4.1(35.3-48.4)$ & $57.4 \pm 6(50-74)$ \\
\hline
\end{tabular}

elastic compressive bandage was applied to those subjects suffering from varicose veins in the lower limbs.

The follow up of the patients who underwent surgery is as follows: 3 months, 6 months, 1 year after surgery and then each year until now.

One hundred and sixty-two patients were regularly present to the annual follow up, 24 patients didn't turn up, therefore, they were contacted by phone.

\section{Results}

In the 30 super obese patients operated on over 5 years ago the average BMI shifted from a preoperative value of $57.4 \mathrm{Kg} / \mathrm{m}^{2}$ (range $50-74$ ) to $38.3 \mathrm{Kg} / \mathrm{m}^{2}$ one year after surgery, to 35.65 years after surgery and to a current value of to $35.9 \mathrm{Kg} / \mathrm{m}^{2}$ (range 23 - 54) with an average \%EWL (Percentage of Excess Weight Loss) of 60.16 (range 34 - 97) (Figures 1 and 2).

In the 156 II and III grade obese patients the average BMI decreased from a preoperative level of $40.7 \mathrm{Kg} / \mathrm{m}^{2}$ (range 35.3 - 48.4) to $26.6 \mathrm{Kg} / \mathrm{m}^{2}$ after one year from surgery, to $26.7 \mathrm{Kg} / \mathrm{m}^{2} 5$ years after surgery and to 27.8 $\mathrm{Kg} / \mathrm{m}^{2}$ (range 19.6 - 35.8) with an average \% EWL of 69.4 (Figures 3 and 4, Table 2).

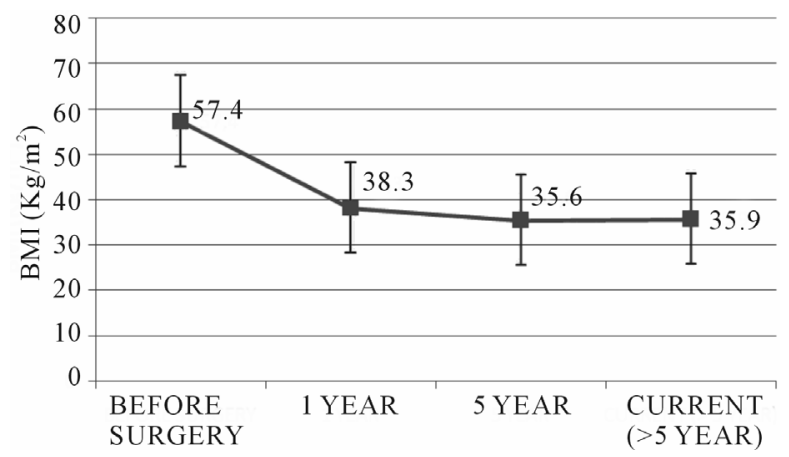

Figure 1. Average BMI (Body Mass Index) in super obese patients with relative primary standard deviation before surgery, 1 year after surgery, 5 years after surgery and today (patients operated on from 5 to 10 years ago).

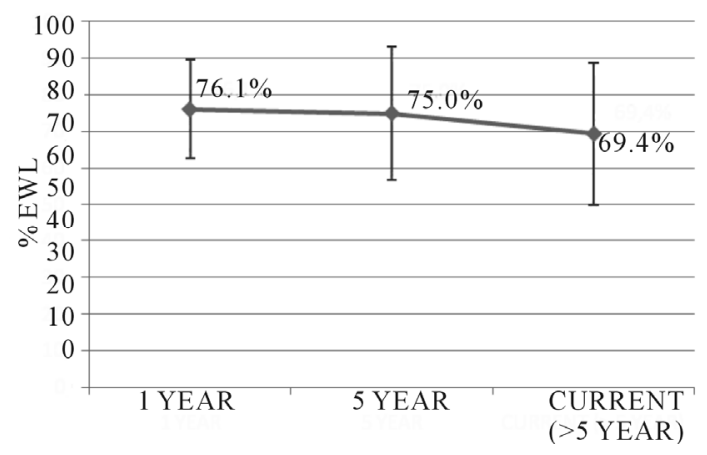

Figure 2. Average \% EWL (Percentage of Excess Weight Loss) of super obese patients with relative standard deviation 1 year after surgery, 5 years after surgery and today (patients operated on from 5 to 10 years ago). 


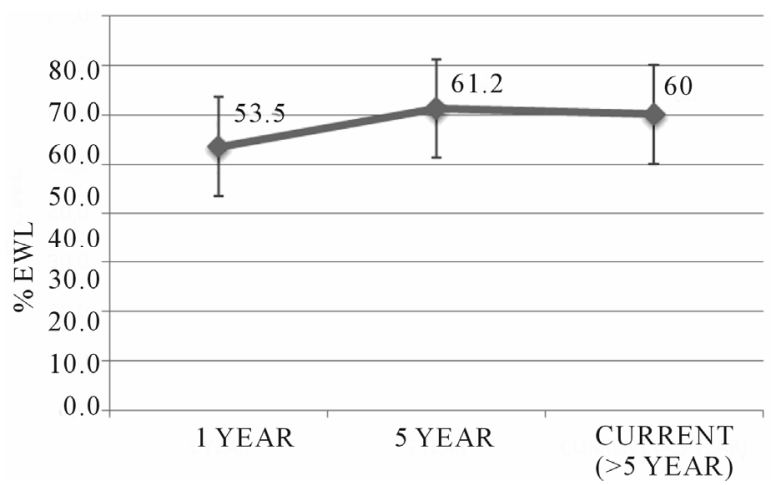

Figure 3. Average BMI (Body Mass Index) of II and III grade obese patients with relative standard deviation, 1 year after surgery, 5 years after surgery and today (patients operated on from 5 to 10 years ago).

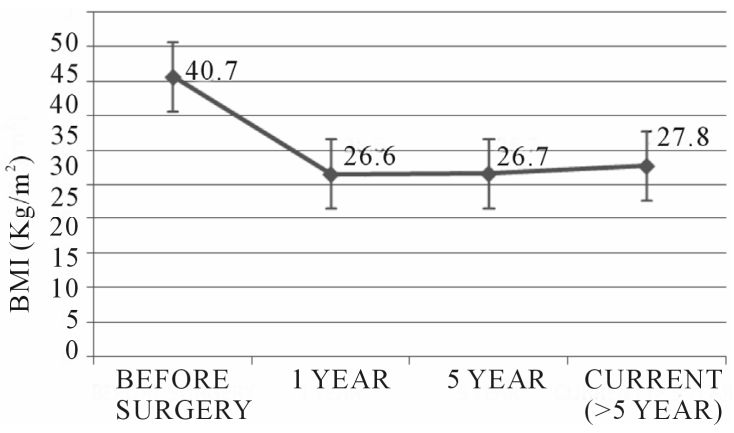

Figure 4. Average \%EWL (Percentage of Excess Weight Loss) of II and III grade obese patients with relative standard deviation, 1 year after surgery, 5 years after surgery and today (patients operated on from 5 to 10 years).

Table 2. Follow-up over 5 years.

\begin{tabular}{lcc}
\hline & Obese (n. 156) & Super Obese (n. 30) \\
\hline Weight $(\mathrm{Kg})$ & $71.8 \pm 12.0(49-94)$ & $99.3 \pm 24.8(56-182)$ \\
BMI $\left(\mathrm{kg} / \mathrm{m}^{2}\right)$ & $27.8 .7 \pm 3.8(19.6-35.8)$ & $35.9 \pm 7.5(23-42)$ \\
\hline
\end{tabular}

From a nutritional point of view there is similar behaviour between super obese and II and III grade obese patients: no deficiency of the main elements (Table 3). Some cases of occasional folic acid and vitamin B12 oral supplementation for 1 - 2 months.

No alterations in the values of parathormones over time.

Out of 5 super obese patients suffering from type 2 diabetes, only one is still under a low hypoglycaemic therapy; the other 4 are not following any therapy over 5 years after the operation.

In super obese patients, the results about other comorbidities of the metabolic disease refer to recoveries from OSAS (Obstructive Sleep Apnea Syndrome) in 90\% of cases, from high blood pressure in $65 \%$, from dyslipidemia in $80 \%$ and hyperuricemia in $85 \%$ of cases.
Table 3. N. 186 patients operated on over 5 years ago. Average nutritional levels before and after Long Magenstrasse.

\begin{tabular}{ccc}
\hline & Before Operation & Current \\
\hline Iron $(\mu \mathrm{g} / \mathrm{dl})$ & 74.81 & 78.24 \\
$\mathrm{Ca}(\mathrm{mg} / \mathrm{dl})$ & 8.98 & 8.91 \\
Vit. $\mathrm{B}_{12}(\mathrm{pg} / \mathrm{ml})$ & 414.12 & 321.36 \\
Folic Acid $(\mathrm{ng} / \mathrm{ml})$ & 5.94 & 4.90 \\
Total Proteins & 7.30 & 6.90 \\
\hline
\end{tabular}

Among perioperative complications we report a suture dehiscence at antral level which was resolved with an urgent surgical revision.

In the 186 patients operated on before October 2008 the most frequent complication, which generally appeared $6-12$ months after surgery, is, generally, the postprandial, and never the nocturnal, gastro-oesophageal reflux ( $9 \%$ of patients who underwent surgery), probably due to a recovered pyloric tone; the treatment is endoscopic and consists in a pneumatic dilation of the pylorus.

In all cases the dumping syndrome was absent.

\section{Discussion}

LM surgical procedure has a mixed type mechanism of action given by the combination of a gastric restriction, entero-hormonal effects, a change in motility, gastric secretion and, obviously, in eating habits.

\subsection{Conservation and Gastric Restriction}

Differently from S.G., where measures of residual stomach are not standardized and each surgeon can choose a distance from the pylorus ranging from 3 to $8 \mathrm{~cm}$ and a calibration bougie ranging from 32 to $50 \mathrm{Fr}$. with great variability in the results especially over time, in the LM, the technique requires specific measures with reproducible results.

The suture-section stretches from the angle of His up to $2-3 \mathrm{~cm}$ from the pylorus with a calibration bougie of 36 Fr. resulting, this way, in a uniformly tubular stomach at the small curvature (food tract). The rest of the stomach (corpus and fundus) is excluded from food transit while still producing gastric juices which flow into the 3 cm dimension prepyloric "Mill" (secretory pathway).

In order to stop the bolus from descending the duodenum and reaching back the excluded stomach, a pyloric divulsion is fundamental because it resolves the pyloric spasm secondary to the vagal nervous interruption; therefore, the food bolus transits easily also thanks to the lack of a prepyloric "pouch" which requires an effective emptying pump. 
This maneuver consisting in the interruption of the fibro-muscular pyloric ring with a craft technique, could be easily criticized, but it is very effective both as a digitoclastic and endoscopic pneumatic-dilator maneuver as confirmed by the daily clinical experience.

Gastric tube peristalsis can thus regularly take place pushing food bolus into the duodenum and limiting oesophageal reflux which would force the subject to assume omeprazole for long periods of time.

Patients who underwent LM do not suffer from night pyrosis and only few cases start intermittent cycles of therapy with omeprazole.

Another important effect of LM is a $20 \%$ - $30 \%$ reduction in the gastric exocrine secretion influenced by selective vagotomy secondary to gastric tubulization.

This reduction makes the production of gastric juices proportional to the quantity of food ingested (restrictive aspect of the LM) creating a balanced mixing at the level of the "Mill".

Gastric conservation acts favorably on the production of the intrinsic factor and thus on vitamin B12.

It should be noted that it is possible to explore through endoscopic route also the part of the stomach excluded from food transit.

\subsection{Mechanism of Actions of Hormones}

As reported by Drazen et al. [8], although ghrelin has not been dosed in the considered patients, it is reasonable to assume that it has an important role in the modulation of appetite. After surgery, in fact, the fundus of the stomach is excluded by the food tract and, consequently, the cells responsible for the secretion of ghrelin are not involved in the stimulation by the food ingested; this aspect inevitably results in a reduced endocrine secretion of ghrelin which determines an inhibition of the hormonal cascade that promotes the sense of hunger. Afterwards, food bolus, thanks to the pyloric divulsion, reaches more rapidly the duodenum and the jejunum, site of GIP (Gastric Inhibitory Polypeptide) and PYY (Peptide YY) synthesis. Reinehr et al. [9] and Valderas et al. [10] showed that a more rapid intestinal transit of the partially digested food bolus through these intestinal tracts triggers an increase in the secretion of GIP and PYY resulting in an early sense of satiety due to hypothalamic stimulation. Moreover, GIP and PYY together with the quick transit of partially digested food, stimulate iliac L cells to secrete GLP-1 (Glucagon-Like Peptide-1), which exerts its secretory effect improving insulin sensitivity and promoting the sense of satiety.

Furthermore, the analysis of the results has underlined that, concurrently to weight loss, patients improve their dyslipidemic pathology by remarkably reducing cardio vascular risks.

\section{Conclusions}

Important characteristics of LM are:

1) Gastric conservation with functionality, though reduced, helps maintain a good metabolic-nutritional balance over time.

2) Tubular prepyloric region remains uniform over time without any possibility of dilation as it can, sometimes, happen in the SG: we believe this to be an essential characteristic to avoid weight gain over time.

Finally, we should underline the high percentage of a good quality of life in terms of food "compliance": eating solid and varied foods.

\section{REFERENCES}

[1] A. A. Gumbs, M. Gagner, G. Dakin and A. Pomp, "Sleeve Gastrectomy for Morbid Obesity," Obesity Surgery, Vol. 17, No. 7, 2007, pp. 962-969.

http://dx.doi.org/10.1007/s11695-007-9151-x

[2] M. Deitel, M. Gagner, A. L. Erickson and R. D. Crosby, "Third International Summit: Current Status of Sleeve Gastrectomy," Surgery for Obesity and Related Diseases, Vol. 7, No. 6, 2011, pp. 749-759. http://dx.doi.org/10.1016/i.soard.2011.07.017

[3] C. Vassallo, G. Berbiglia, A. Pessina, M. Carena, A. Firullo, A. Griziotti, F. Ramajoli, E. Palamarciuc and M. Fariseo, "The Super-Magenstrasse and Mill Operation with Pyloroplasty: Preliminary Results," Obesity Surgery, Vol. 17, No. 8, 2007, pp. 1080-1083.

http://dx.doi.org/10.1007/s11695-007-9182-3

[4] C. Vassallo, G. Berbiglia, M. Carena, "The Long Magenstrasse with Pyloroplasty as Functional Gastric Bypass: 6-Years Experience, 308 Operations," Health, Vol. 2, No. 8, 2010, pp. 935-940.

http://dx.doi.org/10.4236/health.2010.28138

[5] M. Allgöwer, F. Harder, L. F. Hollender, H. J. Peiper and J. R. Siewert, "Trattato di Gastroenterologia Chirurgica," Delfino Antonio, Frosinone, 1984.

[6] K. Tymitz, A. Engel, S. McDonough, M. P. Hendy and G. Kerlakian, "Changes in Ghrelin Levels Following Bariatric Surgery: Review of the Literature," Obesity Surgery, Vol. 21, No. 1, 2011, pp. 125-130. http://dx.doi.org/10.1007/s11695-010-0311-z

[7] A. Bohdjalian, F. B. Langer, S. Shakeri-Leidenmühler, et al., "Sleeve Gastrectomy as Sole and Definitive Bariatric Procedure: 5-Year Results for Weight Loss and Ghrelin," Obesity Surgery, Vol. 20, No. 5, 2010, pp. 535-540. http://dx.doi.org/10.1007/s11695-009-0066-6

[8] D. L. Drazen, T. P. Vahl, D. A. D'Alessio, "Effects of a Fixed Meal Pattern on Ghrelin Secretion: Evidence for a Learned Response Independent of Nutrient Status," Endocrinology, Vol. 147, No. 1, 2006, pp. 23-30. http://dx.doi.org/10.1210/en.2005-0973

[9] T. Reinehr, C. L. Roth, G. H. Schernthaner, H. P. Kopp, S. Kriwanek and G. Schernthaner, "Peptide YY and Glucagon-Like Peptide-1 in Morbidly Obese Patients before and after Surgically Induced Weight Loss," Obesity Sur- 
gery, Vol. 17, No. 12, 2007, pp. 1571-1577.

http://dx.doi.org/10.1007/s11695-007-9323-8

[10] J. P. Valderas, V. Irribarra, C. Boza, R. de la Cruz, Y. Liberona, A. M. Acosta, M. Yolito and A. Maiz, "Medical and Surgical Treatments for Obesity Have Opposite
Effects on Peptide YY and Appetite: A Prospective Study Controlled for Weight Loss," The Journal of Clinical Endocrinology and Metabolism, Vol. 95, No. 3, 2010, pp. 1069-1075. http://dx.doi.org/10.1210/jc.2009-0983 